\title{
UM ESTUDO SOBRE A REVISTA BRASILEIRA DE HISTÓRIA DA EDUCAÇÃO (2001-2017): AUTORIAS, TEMAS E CITAÇÕES ${ }^{1}$
}

\author{
A STUDY ABOUT THE BRAZILIAN JOURNAL OF HISTORY OF \\ EDUCATION (2001-2007): AUTHORS, TOPICS AND QUOTES
}

\section{UN ESTUDIO SOBRE LA REVISTA BRASILEÑA DE HISTORIA DE LA EDUCACIÓN (2001-2017): AUTORÍAS, TEMAS Y CITAS}

\author{
MARISA BitTAR \\ Olivia Morais de Medeiros Neta ${ }^{\mathrm{II}}$ \\ AMARILIO FERREIRA JUNIOR ${ }^{\mathrm{I}}$ \\ ${ }^{\mathrm{I}}$ Universidade Federal de São Carlos, São Carlos/SP - Brasil \\ II Universidade Federal do Rio Grande do Norte, Natal/RN - Brasil
}

Resumo Este artigo é resultado de nossa participação no projeto internacional Mapping the History of Education (2014-2019) e analisa as publicações da Revista Brasileira de História da Educação (RBHE). Como fundamento teórico, baseamo-nos em autores que se dedicaram a compreender o funcionamento do campo científico, como Pierre Bourdieu e Norbert Elias. Foram analisados os artigos publicados entre 2001, data do primeiro número da Revista, e 2017, ano em que fechamos o levantamento. Para classificá-los, adotamos as seguintes nomenclaturas: internacionalização; gênero das autorias; instituições de filiações (nacionais e internacionais); origem geográfica das autorias (países e regiões brasileiras); citações; temáticas; palavras-chave. Além das conclusões referentes a esses indicadores, finalizamos com a reflexão sobre a importância em si do mapeamento dessa produção, acreditando que ele possa contribuir para a formação de grupos, a troca de informações e o intercâmbio que vem sendo praticado em âmbito internacional nessa área de conhecimento.

Palavras-chave: História da Educação; Revista Brasileira de História da Educação; CAMPO CIENTÍFICO.

Aвstract This article is the result of the international project Mapping the History of Education (2014-2019) and analyses the articles published by the Revista Brasileira de História da Educação (RBHE). We are based on authors who have dedicated themselves to understanding

Essa pesquisa contou com financiamento do CNPq.

Comunicações Piracicaba |v. 28 | n. 1 | p. 279-294| jan.-abr. 2021 DOI: http://dx.doi.org/10.15600/2238-121X/comunicacoes.v28n1p279-294 
the scientific field, such as Pierre Bourdieu and Norbert Elias. The articles were published in the period from 2001, when they first appeared, to 2017, analyzed and classified in the following nomenclatures: internationalization; genre of authorship; affiliation institutions (national and international); geographical origin of the authors (Brazilian countries and regions); citations; themes; key words. In addition to the conclusions regarding these indicators, we conclude with the reflection on the importance of the mapping of this production itself, believing that it can contribute to the formation of groups, the exchange of information and the exchange that has been practiced at an international level.

Keywords: History of Education; Brazilian Journal of History of Education; Scientific FIELD.

REsumen Este artículo es el resultado de nuestra participación en el proyecto internacional "Mapeando la Historia de la Educación" (2014-2019) y analiza las publicaciones de la Revista Brasileira de História da Educação (RBHE). Como fundamento teórico, contamos con autores que se han dedicado a comprender el funcionamiento del campo científico, como Pierre Bourdieu y Norbert Elias. Se analizaron los artículos publicados entre 2001, fecha del primer número de la revista, y 2017, año en que cerramos la encuesta. Para clasificarlos, adoptamos las siguientes nomenclaturas: internacionalización; género de autoría; instituciones de afiliación (nacionales e internacionales); origen geográfico de la autoría (países y regiones brasileñas); citas; temático; palabras clave. Además de las conclusiones sobre estos indicadores, finalizamos con una reflexión sobre la importancia del mapeo de esta producción en sí, creyendo que puede contribuir a la formación de grupos, al intercambio de información y al intercambio que se ha practicado a nivel internacional en esta área de conocimiento.

Palabras clave: Historia de la Educación; Revista Brasileña de Historia de la EduCACIÓN; CAMPO CIENTÍFICO.

\section{INTRODUÇÃo}

No Brasil, desde o final da ditadura militar, o campo da história da educação passou por intensa expansão e organização, tornando-se um dos mais atuantes na grande área que compõe a Educação brasileira. Desde 1984, grupos de pesquisa locais, regionais e nacionais funcionam em todo o País (HAYASHI; FERREIRA Jr., 2010). O crescimento da pesquisa nessa área, aliado ao fato de que o ensino de História da Educação está presente em todos os cursos de formação de professores, explica a criação, entre 1997 e 2015, de cinco revistas nacionais dedicadas à História da Educação (HAYASHI; FERREIRA Jr., 2010)². Esse fato por si só expressa a mudança operada na forma de divulgação do conhecimento científico no Brasil se considerarmos, por exemplo, o padrão que vigorava antes da criação dos Programas de Pós-Graduação quando os livros eram o veículo principal, o que denotava também um tipo distinto de produção do conhecimento. Para a grande área de Ciências Humanas essa mudança

2 As referidas revistas são: Revista HISTEDBR On-line (1991), Revista História da Educação (1997), , Revista Brasileira de História da Educação (2001), Cadernos de História da Educação (2002), Revista de História e Historiografia da Educação(2015). 
não ocorre sem tensões, uma vez que a tradição anterior, marcada por ritmos de publicação mais longos, contrasta hoje com a pressão por publicações cada vez mais céleres e nesse cenário os periódicos assumiram o papel principal.

Para compreendermos o papel das revistas acadêmicas, é preciso um entendimento prévio sobre o próprio funcionamento do campo científico. Sendo assim, em termos conceituais, baseamo-nos em dois autores, Pierre Bourdieu (1994) e Norbert Elias !994) que, a nosso juízo, contribuem para esse entendimento e para as relações que, no seu interior, se estabelecem entre aqueles que o compõem. Para Bourdieu (1994), a disputa pelo monopólio da competência científica caracteriza as relações inerentes às atividades de pesquisa já que o campo científico é um campo como outro qualquer, porém, com suas próprias variáveis, particularmente no que se refere à concorrência que se estabelece entre os pares. Por sua vez, Norbert Elias (1994), ao discorrer sobre configuração, nos instiga a pensar que estas são formadas por grupos interdependentes (no caso, grupos de pesquisadores e suas conexões institucionais), organizados coletivamente e não por indivíduos singulares, sendo a configuração e as relações estabelecidas no campo científico um espaço de síntese sempre provisória do movimento dialético da realidade. Para esse espaço social e de síntese, a comunicação científica é vital para o avanço e o desenvolvimento da ciência, uma vez que é "por seu intermédio que ocorre a disseminação, a interação da comunidade científica e a legitimação pelos pares, consolidando assim a geração de novos conhecimentos" (ALMEIDA, 2006, p. 28). Essa produção pressupõe, portanto, uma pluralidade de indivíduos, conforme explica Norbert Elias:

Dizer que os indivíduos existem em configurações significa que o ponto de partida de toda investigação sociológica é uma pluralidade de indivíduos, os quais, de um modo ou de outro, são interdependentes. Dizer que as configurações são irredutíveis significa que nem se pode explicá-las em termos que impliquem que elas têm algum tipo de existência independente dos indivíduos, nem em termos que impliquem que os indivíduos, de algum modo, existem independentemente delas (ELIAS, 1994, p. 184).

O cerne das variáveis consideradas por Bourdieu (1994) está relacionado à construção de hegemonias, as quais, ao longo desse processo e uma vez estabelecidas, determinam aos pesquisadores os temas a serem investigados, além de métodos e estratégias, indissociavelmente políticos e científicos. Sendo assim, as revistas de um determinado campo científico, por serem espaços de veiculação do conhecimento produzido, permitem a visualização desse campo como também a sua compreensão. Dessa maneira, o nosso propósito foi analisar a Revista Brasileira de História da Educação (RBHE) como veículo de difusão da produção da área de História da Educação, o que nos possibilita conhecer também o próprio campo de saber da história da educação. Para tanto, optamos por identificar autorias, temas e citações, com especial atenção ao aspecto da internacionalização. ${ }^{3}$

3 Sobre artigos correlatos destacamos: VIEIRA, Carlos Eduardo; GONDRA, José G. (2015). Revista Brasileira de História da Educação: trajetória e os desafios da internacionalização (2001-2014); BITTAR, Marisa; SILVA, Márcia Regina; HAYASHI, M. C. P. I. (2011). Produção científica em dois periódicos da área de educação. Além disso, há pesquisas desenvolvidas no âmbito do projeto "Por uma história dos Congressos Brasileiros de História da Educação (2000-2015)", financiado pela Propesq / UFRN e coordenado pela professora Olivia Morais de Medeiros Neta. 
A opção pela análise das publicações da RBHE justifica-se por este ser o periódico da Sociedade Brasileira de História da Educação, que reúne, desde a sua fundação (1999), grande número de sócios e participantes em congressos científicos destacando-se por sua organização e produção acadêmica. Outra justificativa para essa escolha deve-se ao fato de a RBHE ter se auto-definido como "a única revista acadêmica brasileira especializada na temática da história da educação” no Brasil (RBHE, 2009, p. 9), embora, depois, reconhecesse que outros periódicos também se dedicassem a essa produção.

A Revista Brasileira de História da Educação é um dos periódicos cuja existência está relacionada à expansão dos cursos de Pós-Graduação nas universidades brasileiras a partir da década de 1990. Nesse cenário, insere-se a história da educação como expressiva subárea da Educação, seja como disciplina (ensino) ou pesquisa. A disciplina está presente em todos os cursos de formação de professores no Brasil desde 1928. Como atividade de pesquisa, a história da educação se fortaleceu com a criação do Grupo de Trabalho de História da Educação (ANPEd, 1984), Grupo de Estudos e Pesquisas História, Sociedade e Educação no Brasil/HISTEDBR (1986) e Sociedade Brasileira de História da Educação (SBHE, 1999) a qual, por sua vez, criou a Revista Brasileira de História da Educação (RBHE) após o I Congresso Brasileiro de História da Educação, realizado no Rio de Janeiro, em novembro de 2000. Circulando inicialmente com periodicidade semestral, o primeiro número da revista foi publicado em junho de 2001.

A RBHE publica artigos, dossiês, traduções, resenhas e notas de leitura inéditas no Brasil, relacionados à história e historiografia da educação, de autores brasileiros ou estrangeiros, escritos em português ou espanhol, reservando-se o direito de encomendar trabalhos e compor dossiês (SAVIANI; CARVALHO; VIDAL, 2011). Sediada atualmente na Universidade Estadual de Maringá, a RBHE constitui-se em veículo de divulgação da produção científica nacional e internacional sobre história e historiografia da Educação. Quanto aos dados que aqui apresentamos, foram coletados no site da Revista, que disponibiliza na íntegra todos os artigos publicados desde o primeiro número de sua edição.

Além dos autores que nos dão suporte para o estudo dos artigos da RBHE como parte do campo científico brasileiro, recorremos também à análise bibliométrica que permite, entre outros aspectos, mapear um campo científico e analisar os diversos componentes que operam em sua constituição, tal como o comportamento dos pesquisadores em suas decisões para a construção do conhecimento. Vale lembrar que essas decisões, conforme Bourdieu (1994), não decorrem exclusivamente da vontade de quem pesquisa. A opção pode parecer livre, mas não é: está imbrincada nas relações que configuram o campo, o qual já está composto quando do nosso ingresso individual nele. Sendo assim, já existem, na lógica do seu funcionamento, temas, metodologias, teorias e interesses constituídos. Esses elementos em seu conjunto é que sinalizam possibilidades ou não de novos ingressos e construções de carreiras no campo.

Quanto ao recurso à bibliometria, conforme Vanti (2002), ela permite estabelecer relações e análises a partir de contagens estatísticas de publicações ou de elementos extraídos dessas publicações e tem por objetivo medir as produções da pesquisa científica e tecnológica, por meio de dados originados não somente da literatura científica, mas também das patentes. Nessa coleta consideramos características gerais dos artigos publicados na Revista Brasileira de História da Educação, tais como: ano e edições, número de artigos, de dossiês, de resenhas e de notas de leitura bem como os temas privilegiados nos dossiês. 
A sistematização dos dados de autoria, de título, das palavras-chave, de filiação institucional, de local, de ano de publicação e de tipo de publicação das comunicações cientificas da RBHE foi finalizada em 2017. Em seguida, até 2019, apresentamos os resultados no International Standing Conference for the History of Education (ISCHE), especificamente no Grupo de Trabalho Mapping the History of Education (HOFSTETTER; FONTAINE; HUITRIC, 2104), do qual participamos desde a sua criação, em Londres, no ano de 2014. Os trabalhos desse Grupo reuniram pesquisadores de várias partes do mundo e foram concluídos em 2019 na Conferência do Porto, ocasião em que apresentamos os dados deste artigo e que sintetizam, portanto, a nossa participação no projeto Mapping the History of Education (2014-2019) (HOFSTETTER; FONTAINE; HUITRIC, 2104) ${ }^{4}$. Analisamos 439 publicações, distribuídas em 45 volumes e 17 números. Os dados foram organizados em planilhas do Excel e, posteriormente submetidos a análises para a verificação das palavras-chave mais frequentes coletadas no Portal. Fizemos uso também de um software de análise qualitativa, o NVivo. ${ }^{5}$

A apresentação dos resultados está dividida em três partes: 1) indicadores de autoria; 2) indicadores dos artigos; 3) indicadores das citações realizadas pelos autores.

\section{INDICADORES DE AUTORIA}

Inicialmente, chamamos a atenção para o fato de que, ao lidarmos com autorias, estamos lidando com gêneros. Essa questão é de capital importância neste estudo e está no cerne de nossas preocupações no que diz respeito ao conhecimento das autorias presentes no campo. Esclarecemos, assim, que devido à especificidade da língua portuguesa e para facilitar a leitura, considerando as inúmeras menções ao longo do texto, seguiremos as suas regras no que diz respeito ao emprego de plurais e dos termos comuns, deixando claro, contudo, que embora alguns termos sejam grafados no masculino, eles referem-se igualmente ao gênero feminino.

No Brasil, a questão da autoria na área das Ciências Humanas tem merecido reflexões mais sistemáticas nos últimos anos em decorrência do crescimento da produção de teses e dissertações que, por sua vez, geram inúmeros artigos. A produção científica atual é de tal monta que se torna impossível para um único pesquisador realizar o seu levantamento completo e, principalmente, a sua análise. Além da grande quantidade de teses e dissertações, há centenas de livros, capítulos de livros e artigos publicados regularmente em periódicos, fato que requer um esforço coletivo e sistemático em estudos que pretendam mapear essa produção. No entanto, se para o pesquisador iniciante a sua inserção no cenário científico depende de seu ingresso em um grupo de pesquisa preferencialmente consolidado, isso apenas caracteriza a forma de produção predominante hoje, pois, no passado, simplesmente inexistiam esses grupos. Para alguns pesquisadores, todavia, principalmente aqueles já consagrados, o grupo de pesquisa não representa uma vantagem para a construção do nome. Pois, como escreveu Pierre Bourdieu, o nome construído individualmente proporciona maiores ganhos simbólicos, já que ao ingressar no campo científico, ninguém postula o anonimato ${ }^{6}$.

4 Este artigo foi primeiramente submetido à RBHE, que o recusou.

5 Software disponível em: <http://www.qsrinternational.com/>. Acesso em: 20 nov. 2017.

6 BOURDIEU, 1994, p. 122-155. 
Em relação ao gênero das autorias que analisamos, foi observada predominância feminina $(52,9 \%)$. Uma hipótese para essa predominância pode ser o fato de que os pesquisadores de história da educação no Brasil têm provindo mais dos cursos de Pedagogia (historicamente de composição feminina) do que dos cursos de História. ${ }^{7}$. Além desse fator, há que se considerar também o ingresso no ensino superior e nos cursos de Pós-Graduação, âmbitos nos quais a maioria é composta por mulheres, sobretudo em cursos da área de Humanas e de Educação. Levantamentos mostram ainda que a maioria dos artigos científicos publicados no País têm mulheres como autoras. Desse modo, a tendência na RBHE confirma o que se verifica na produção acadêmica brasileira em geral.

Outro aspecto observado foi a vinculação institucional dos autores, que mostrou concentração da Universidade de São Paulo, Universidade Federal de Minas Gerais e Universidade do Estado do Rio de Janeiro. Pela análise da procedência institucional dos autores que publicaram na RBHE de 2001 a 2017, contatamos a seguinte distribuição regional: Sudeste (59\%), Sul $(15 \%)$, Nordeste $(8 \%)$, Centro-Oeste $(3 \%)$ e Norte $(1 \%)^{8}$. Percebe-se, pois, sub-representação da maioria das regiões. Quando a revista passou a circular em período quadrimestral, o Editorial de 2009 assim tratou a questão: “o projeto editorial procura garantir ampla diversidade institucional dos autores filiados a instituições de pesquisa e ensino nacionais e estrangeiras. Com efeito, no período de 2005 a 2008, a RBHE contou com a participação de pesquisadores de 29 instituições de ensino superior brasileiras, com a predominância de programas de pós-graduação de universidades públicas".

Os dados citados no Editorial reforçam a nossa hipótese sobre a procedência da maioria dos artigos como resultado de teses e dissertações. Pois, as exigências da CAPES pressionam não apenas docentes como também alunos de Mestrado e Doutorado a rapidamente publicarem partes de suas pesquisas na forma de artigos. Nesse sentido, é importante considerarmos o crescimento quantitativo de estudantes nessas duas modalidades desde a década de 1990 devido à expansão dos Programas de Pós-Graduação em Educação pelo interior do País.

Nessa perspectiva, realçamos que o campo científico possui uma lógica própria e relativamente autônoma, uma vez que se constituiu como "um mundo social como os outros, mas que obedece a leis sociais mais ou menos específicas" (Bourdieu, 1994, p. 20). Assim, a capacidade de "produzir ciência", por parte de um determinado indivíduo ou grupo, está agregada a um determinado poder social e seus movimentos.

No período de 2001 a 2017 foram listadas 123 instituições nacionais e internacionais cujos artigos são provenientes. E, de conformidade com a prevalência de publicações nas Regiões Sudeste e Sul, constatamos que os autores com maior número de publicações também possuem vinculação institucional nessas regiões. Vejamos a Tabela 1:

7 A análise sobre gênero dos autores citados foi dificultada pelo sistema vigente de citação sobrenome e inicial do nome (ex: FREIRE, P.), o que não permite distinguir autoria feminina de masculina a não ser em casos de nomes sobejamente conhecidos, como BOURDIEU, P. (masculina) ou ROMANELLI, O. (feminina). Essa forma técnica contrasta com as necessidades da vida comum, pois nela, quando nos referimos a uma pessoa, queremos saber nome e sobrenome. Da mesma forma, se queremos conhecer autoria dos gêneros presentes em uma revista, esse dado é de capital importância.

8 A soma absoluta ultrapassa os $100 \%$. Tal fato ocorre pela aproximação das casas decimais ao número inteiro mais próximo. 
Tabela 1: Número de publicação por autores na RBHE.

\begin{tabular}{l|c|l}
\hline \multicolumn{1}{c|}{$\begin{array}{c}\text { Autores com maior número de } \\
\text { publicações na RBHE }\end{array}$} & $\begin{array}{c}\mathbf{N}^{\mathbf{0}} \text { total de } \\
\text { publicações }\end{array}$ & $\begin{array}{l}\mathbf{N}^{\mathbf{0}} \text { de publicaç̃̃es } \\
\text { em coautoria }\end{array}$ \\
\hline Diana Gonçalves Vidal (USP) & 6 & 1 \\
\hline Maria Cristina Soares de Gouvêa (UFMG) & 6 & 2 \\
\hline Rosa Fátima de Souza (UNESP) & 6 & 2 \\
\hline Sonia de Castro Lopes (UFRJ) & 6 & 2 \\
\hline Vera Lúcia Gaspar da Silva (UDESC) & 5 & 3 \\
\hline André Luiz Paulilo (UNICAMP) & 4 & 4 \\
\hline Cynthia Greive Veiga (UFMG) & 4 & 4 \\
\hline Diogo da Silva Roiz (UEMS) & 4 & 4 \\
\hline Luciano Mendes de Faria Filho (UFMG) & 4 & 3 \\
\hline Macioniro Celeste Filho (UNESP) & 4 & 4 \\
\hline Mirian Jorge Warde (PUC-SP) & 4 & 2 \\
\hline
\end{tabular}

Fonte: RBHE. Elaboração dos autores.

Vemos, assim, que apenas um dos autores, dentre os que constam com maior número de publicação, não é da região Sudeste e, sim, do Centro-Oeste (UEMS). Independentemente das questões que permeiam a formação de grupos de pesquisa, eles se tornaram disseminadores da produção realizada, conforme já demonstrado em outros estudos (HAYASHI; FERREIRA Jr., 2010). No entanto, um dado significativo que nossa pesquisa revelou foi que, apesar de os pesquisadores participarem desses grupos, a autoria individual ainda é predominante, perfazendo o total de $74 \%$ das publicações, conforme mostra o Gráfico 1:

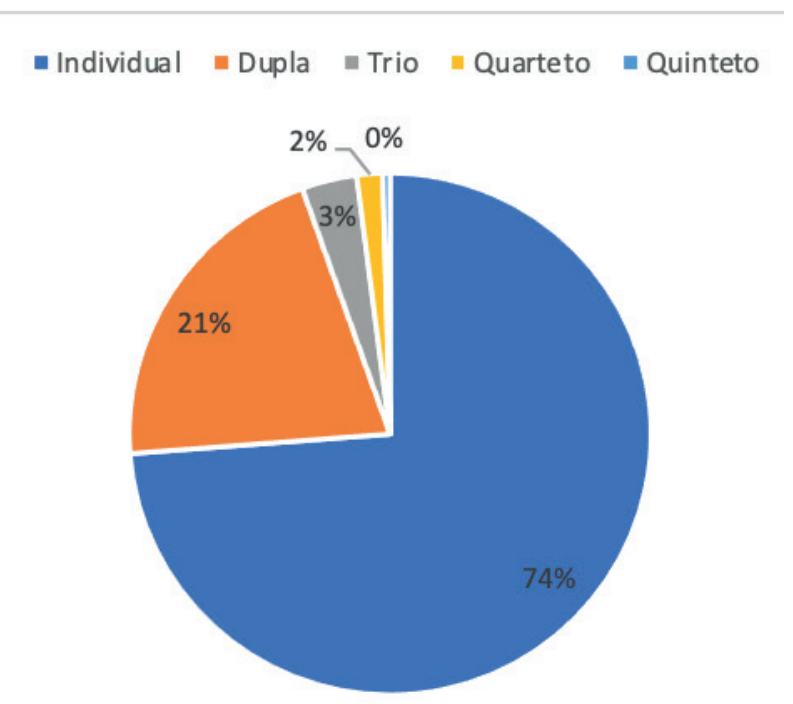

Gráfico 1: Distribuição e concentração das publicações

Fonte: RBHE. Elaboração dos autores. 
Com os resultados obtidos, inferimos que a pressão pela publicação relacionada às dinâmicas de avaliação dos órgãos de fomento às pesquisas e à expansão da Pós-Graduação do Brasil, tem afetado diretamente o comportamento da publicação, uma vez que constatamos aumento da autoria coletiva, predominantemente de coautoria em dupla representada em $21 \%$ das publicações na RBHE. Pesquisas correlatas anteriores à nossa vêm confirmando esse comportamento (HAYASHI; FERREIRA Jr., 2008) embora ressaltem que o padrão de publicação varia de acordo com as áreas de conhecimento, tendo predominado pelo menos até 2008 autorias individuais nas Ciências Humanas e Sociais.

\section{INDICADORES DOS ARTIGOS}

Nosso levantamento evidenciou grande quantidade de temas tratados nos artigos, aspecto valorizado pela RBHE no editorial de 2008 ocasião em que foi reafirmada "a pluralidade de perspectivas, temas e fontes que tem caracterizado essa comunidade de pesquisadores nos últimos anos" (RBHE, Editorial. 2008, p. 9).

Procuramos observar os temas dos artigos por meio dos títulos e das palavras-chave indicadas pelos autores. A visão desse conjunto se caracteriza pela dispersão temática, não tendo sido possível verificar se houve predominância de um tema em relação a outro, dada a quantidade e variedade deles. A própria política da Revista é caracterizada por postular um amplo leque temático, conforme se lê: "na RBHE são veiculadas pesquisas sobre temas de interesse da área de educação, que, todavia, ultrapassam esse campo de investigação para abordar temas variados, tais como instituições escolares, políticas educacionais, pensamento educacional, culturas e práticas escolares, educação comparada, profissão docente e saberes escolares, formação de professores, currículo, ensino-aprendizagem, leitura e escrita, metodologias de ensino" (RBHE, Editorial, 2009, p. 9-13). Chamamos a atenção aqui para o fato de que em 2009 a Revista já circulava em período quadrimestral, fato que se deveu ao aumento da produção advinda dos cursos de Pós-Graduação nos quais predominam a mesma variedade temática.

A palavra-chave História da Educação está presente em 4,3\% dos artigos, e Educação,

em 2,6\% dos artigos. Esse resultado demonstra que a área de abrangência da Revista (História da Educação) é também indicada como palavra-chave dos artigos, o que remete à função da RBHE como veículo de difusão do conhecimento no campo história da educação no Brasil. Ou seja, uma parte significativa de autorias expressa o entendimento de que, qualquer que seja o tema do artigo, ele se refere à história da educação.

Quanto aos temas mais específicos, conforme dados de Bittar, Silva e Hayashi (2011) até 2010 foram identificados Cultura Escolar, Manuais, Historiografia e Formação de Professores, com presença em 2\% dos artigos, Instrução Pública (1,7\%) e Escola Primária (1,4\%). Em temas com porcentagem menor que 1\%, predominaram: Educação Comparada, História da Escola, Reformas Educacionais, Fontes, Escola Nova, entre outros. O tema ensino geralmente está relacionado às reformas estaduais.

Nossos levantamentos até 2017 confirmaram essas tendências. Pela análise da recorrência das palavras-chave percebemos que a associação temática com "história da educação" prevaleceu, o que se deve ao escopo da RBHE, mas vinculados a esse eixo central, os temas mais recorrentes foram: cultura escolar, formação docente, instrução pública, historiografia, escola primária, memória, práticas e política educacional. Na Figura 1 destaca-se a dispersão temática 
presente nas publicações, uma vez que quanto mais citadas as palavras-chaves mais próximas ao centro e com maior tamanho na nuvem de palavras.

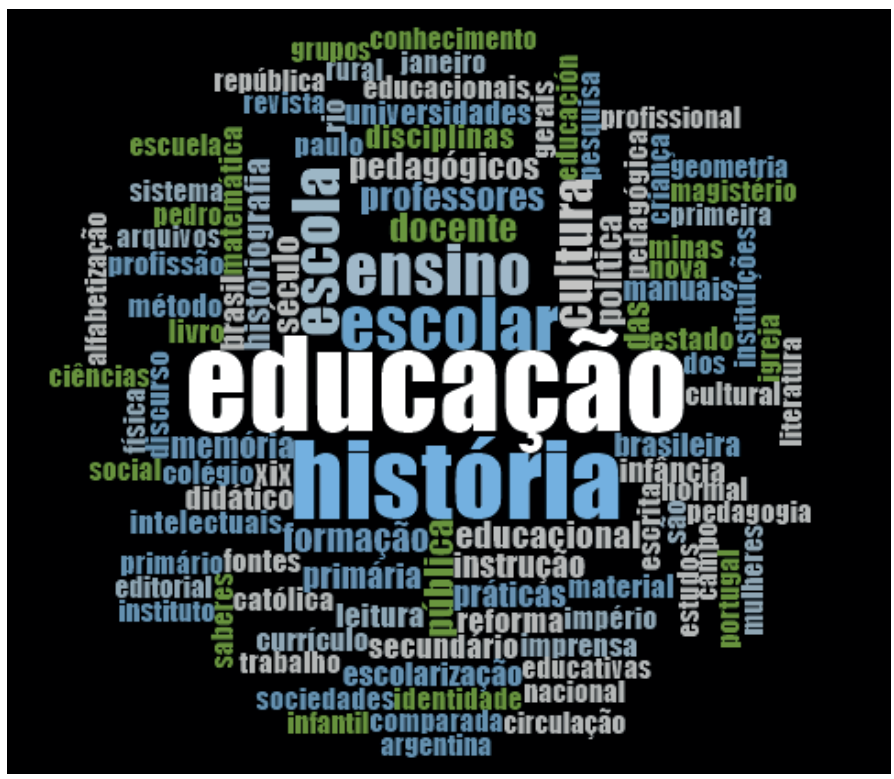

Figura 1: Nuvem de palavras construída a partir das 50 palavras-chave mais recorrentes nas publicações da RBHE

Fonte: RBHE. Elaboração dos autores.

Um aspecto que vem sendo crescentemente colocado em pauta aos pesquisadores desse campo é o que se refere à sua internacionalização, exigência cada vez mais presente nas políticas de Pós-Graduação brasileira. Sobre isso, a RBHE no editorial de n 20 afirma que o periódico quadrimestral da Sociedade Brasileira de História da Educação (SBHE), entidade que tem como objetivos congregar pesquisadores e docentes em história da educação e estimular estudos interdisciplinares, promovendo intercâmbios com entidades congêneres nacionais e internacionais e especialistas de áreas afins. Tal afirmação se expressa na ascendente presença de publicações internacionais e na diversidade crescente de procedência dos autores estrangeiros na RBHE. Conforme o Quadro 1, verificamos que os autores portugueses foram os mais presentes nos artigos que analisamos.

Quadro 1: Autores estrangeiros com maior número de publicações na RBHE

\begin{tabular}{|l|c|}
\hline \multicolumn{1}{|c|}{ Autores } & Número de publicação \\
\hline Adrían Ascolani (Argentina) & 2 \\
\hline Anne-Marie Chartier (França) & 2 \\
\hline António Gomes Ferreira (Portugal) & 2 \\
\hline Carlos Manique da Silva (Portugal) & 2 \\
\hline Jean Hébrard (França) & 2 \\
\hline Jorge M. Nunes Ramos do Ó (Portugal) & 2 \\
\hline Lucía Martínez Moctezuma (México) & 2 \\
\hline
\end{tabular}

Fonte: RBHE. Elaboração dos autores. 
Disso decorre a constatação de que o maior intercâmbio internacional no período foi feito em língua portuguesa, tendência que vem sendo intensificada. A parceria com o campo acadêmico português vem se sobressaindo desde o dossiê História da profissão docente no Brasil e em Portugal (2007) que "inaugurou uma série de artigos sobre projetos de intercâmbio entre pesquisadores brasileiros e portugueses" (SOCIEDADE BRASILEIRA DE HISTÓRIA DA EDUCAÇÃO - SBHE, 2017). Em segundo lugar, o intercâmbio internacional de maior expressão ocorreu com pesquisadores de língua espanhola, destacando-se Espanha e Argentina, conforme Gráfico 3:

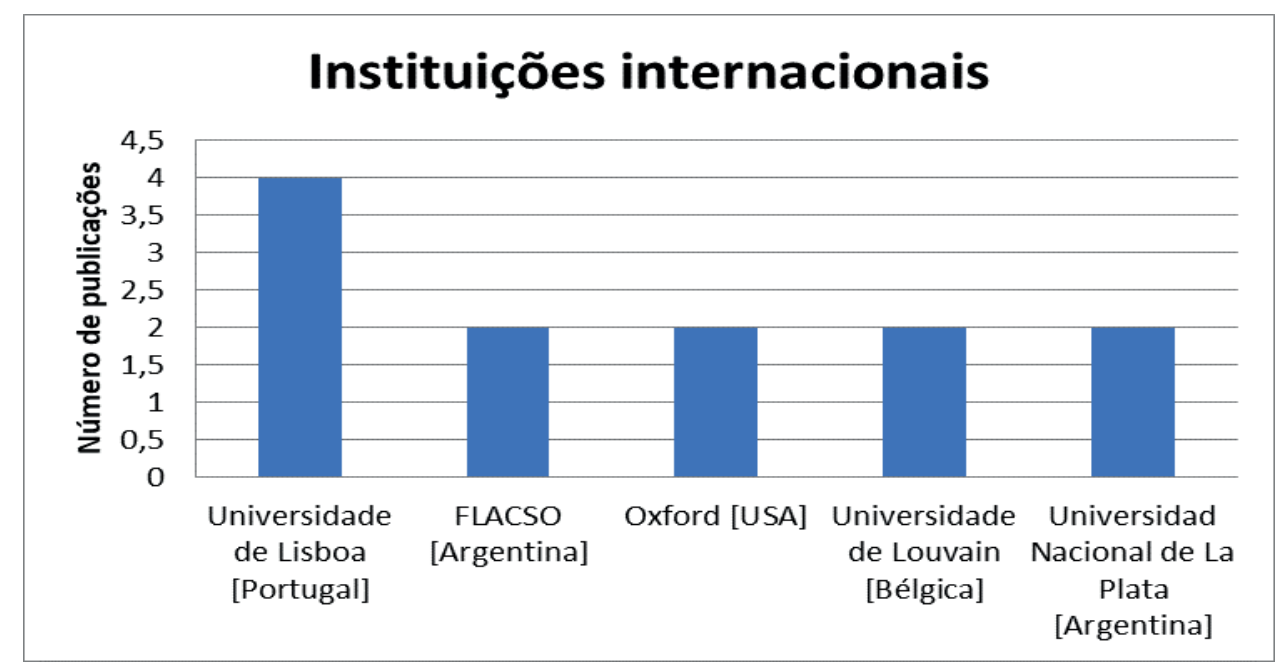

Gráfico 3: Instituições internacionais e as publicações na RBHE.

Fonte: RBHE. Elaboração dos autores.

Constam, como se vê, autores da Bélgica, França, e EUA, fator que representa os esforços de internacionalização empreendidos pelo campo, mas ainda aquém das crescentes exigências das políticas governamentais, principalmente com língua inglesa.

No que diz respeito à autoria estrangeira, chama a atenção o fato de que as publicações individuais predominam sobre as coletivas, sendo $76 \%$ individuais e $24 \%$ em coautoria, a exemplo do movimento que ocorre com as publicações oriundas dos autores brasileiros.

Em relação aos instrumentos de coleta de dados, predominou o documento como fonte de pesquisa, oficial ou não. No tocante a esse aspecto, percebemos que os artigos refletem a intensa discussão sobre novos objetos e alargamento do conceito de fonte que marcou a pesquisa em história da educação no Brasil na década de 1990. Pois a variedade das fontes contrasta com o que, anteriormente, se convencionou designar como história positivista, isto é, baseada em documentos oficiais. Acrescentamos ainda, quanto às metodologias empregadas, que mais de 98\% dos artigos indicaram como procedimento a pesquisa bibliográfica.

Quanto aos referenciais teóricos, predominou a História Cultural, aspecto que buscamos captar por meio dos autores citados, palavras-chave ou resumos dos artigos. Outros referenciais, como o próprio marxismo, que já foi expressivo nesse campo, pouco aparecem, denotando a hegemonia do culturalismo no campo da história da educação brasileira desde a 
década de $1990^{\circ}$. Sobre a presença do marxismo na época dos primeiros Programas de Pós-Graduação em Educação, Silvio Gamboa afirmou que no período de 1977-1980, surgiram as primeiras dissertações cujo referencial teórico era o materialismo histórico e que representavam 30\% no PPGE da UFSCar (área de Pesquisa Educacional), "[...] 16\% na área de Filosofia da PUC-SP, 30\% na área de Pesquisa Educacional da UFSCar e 28\% na área de Metodologia de Ensino da UNICAMP” (Gamboa., 2000, p. 111).

Tal como procedemos com os referenciais, buscamos conhecer também os períodos mais pesquisados, constatando que a maioria dos artigos focalizou temas relacionados ao século XX. De fato, confirmando nosso levantamento, o Editorial de 2014 informou que "esta edição volta a destacar o século XX”. Essa tendência já vinha sendo observada desde 1990, pois, pelo menos no tocante às dissertações elaboradas nos Programas de Pós-Graduação em Educação, outros trabalhos mostraram que vinha ocorrendo dominância de recortes sobre a conjuntura presente e diminuição de estudos historiográficos sobre períodos mais recuados no passado. Reforçando essa tendência, estudo sobre os trabalhos apresentados na SBHE em João Pessoa (2017), constatou que o período republicano brasileiro foi o mais pesquisado enquanto o colonial e imperial raramente apareceram ${ }^{10}$. Esse estudo ratificou o levantamento de Miriam Warde publicado na revista Em Aberto (1990) no qual constatou que oitenta por cento dos trabalhos vinculados a cursos de Pós-Graduação a partir de 1970 referiam-se ao período republicano.

A preferência pela contemporaneidade, tendência que, como afirmamos, já vinha se expressando há alguns anos, foi confirmada pelos dados. Por exemplo, dentre os artigos analisados, 45,8\% trataram do século XX, enquanto apenas 3,4\% focalizaram os séculos XVI, XVII e XVIII. Nossos levantamentos mostram também que o século XIX tem sido objeto de interesse crescente entre os historiadores da educação brasileira, enquanto o XXI, por sua vez, começa a aparecer.

A investigação sobre a abrangência geográfica do objeto de estudo dos artigos analisados objetivou verificar em que medida realidades externas ao Brasil são temas estudados por pesquisadores brasileiros. No caso aqui analisado, observamos que, por ser um periódico de circulação nacional, a maioria dos artigos da RBHE desenvolveu temáticas relacionadas ao Brasil: 72,3\%. A grande porcentagem de artigos em que não foi identificada a localidade a que a pesquisa se referia foi atribuída àquelas que tratam de temáticas gerais, não-associadas a um local específico. Acrescentamos ainda que 3,6\% dos artigos tiveram como foco de pesquisa a França e a Argentina, 2,4\% os Estados Unidos e a Europa (sem determinação do país).

\section{INDICADORES DAS CITAÇÕES}

Levando em conta as possibilidades de análise obtidas com o estudo das citações e a importância da citação bibliográfica dentro de um campo de pesquisa, recorremos a essa metodologia e concluímos que a autoria das citações nos artigos é do tipo individual, coletivo ou institucional, predominando a primeira. Eis as percentagens: 80,7\% de tipo individual; 7,3\% de tipo coletiva; 3,5\% de tipo institucional e 8,4\% não determinado.

\footnotetext{
9 Sobre a influência do marxismo no âmbito da pesquisa em educação no Brasil, consultar. FERREIRA Jr. (2012); FERREIRE Jr. (2017).

10 BITTAR, 2019, p. 231 et seq.
} 
Quanto aos autores citados, trata-se de um aspecto importante por ser um indício direto ou indireto dos referenciais teóricos empregados nos artigos. Nesses termos, no que se refere a autores estrangeiros, os mais citados foram: Roger Chartier, Pierre Bourdieu, Michael Foucault, António Nóvoa, André Chervel, Peter Burke, Michael de Certeau, E. P. Thompson, John Dewey, Antonio Gramsci, Mario Alighiero Manacorda, Franco Cambi, Deleuze, Norberto Bobbio, Popkevitz, George Duby, Norbert Elias, e Éric Hobsbawn.

Dentre os brasileiros, observamos com maior predominância: Clarice Nunes, Denice Catani, Maria Marta Chagas de Carvalho, Diana Gonçalves Vidal, Cynthia Greive Veiga, Luciano Mendes de Faria Filho, Miriam Jorge Warde, Dermeval Saviani, Fernando de Azevedo, Manuel B. Lourenço Filho, Anísio Teixeira, Carlos Roberto Jamil Cury, Jorge Nagle. No entanto, é importante frisar que, além de crescer o número de autores citados em cada artigo, esse crescimento parece comportar a diversidade de novas autorias provenientes de pesquisas de Mestrado e Doutorado.

Quanto à autoria institucional, refere-se às obras publicadas por instituições governamentais ou privadas. Dentre os documentos citados, destacamos os produzidos pela União $(0,4 \%)$ e pelas unidades federativas brasileiras, destacando-se São Paulo, Paraná, Minas Gerais e Mato Grosso. Os documentos com autoria "Brasil" referem-se a publicações de leis e regulamentos de caráter nacional. Os artigos indicam que foram utilizados também acervos de escolas, fontes legislativas, fotografias e jornais, fato que atesta a grande variedade de fontes com as quais os historiadores da educação brasileira vêm trabalhando bem como a atenção dispensada a arquivos das mais diversas proveniências.

Em relação às tipologias das fontes citadas, constatamos variedade também: livros, artigos, capítulos de livro, textos que circulam na Internet, trabalhos apresentados em evento, dissertações, teses, jornal, folder, panfletos, relatórios, palestras, programa de TV, entrevistas etc. No padrão de citação, há maior percentual de citação de livros $(56,7 \%)$ do que a citação de artigos em periódicos (13,9\%). Desse modo, constatamos que, apesar da exigência de publicação de artigos, os pesquisadores desse campo, em contraste com os de outros, continuam considerando os livros como veículos muito importantes. São baixas as citações de teses e de dissertações, como também de trabalhos apresentados em eventos, indicando que esse tipo de fonte é pouco consultado nas pesquisas em história da educação. O uso de documentos disponíveis na rede mundial de computadores também foi reduzido, fator que pode demonstrar a necessidade típica desse campo de pesquisar em fontes primárias e consultar fontes impressas. Verificamos ainda grande representatividade de fontes internacionais (59\%), ou seja, citações de autores estrangeiros. Apesar dessa porcentagem, a maioria das citações encontra-se no idioma português.

\section{Conclusões}

Embora não fosse um aspecto que nos interessasse no início da pesquisa, o levantamento que efetuamos trouxe evidências para constatarmos, inicialmente, que o fato de a RBHE ter passado a ser quadrimestral a partir de 2008 foi o aumento da produção de teses, dissertações e trabalhos apresentados nos Congressos bianuais da SBHE e do Congresso Luso-Brasileiro de História da Educação. A pressão por publicação associada ao crescimento desse tipo de produção gerou pressão também sobre as revistas. No caso da RBHE, paralelamente à impor- 
tância e crescimento numérico dos congressos, ela passou a ser um dos desaguadouros de trabalhos apresentados nos diversos âmbitos de eventos acadêmicos e se tornou um dos veículos preferenciais de compartilhamento da produção acadêmica em história da educação no Brasil.

No que se refere à questão das autorias, os artigos que analisamos mostram que predominaram as individuais tanto na publicação como na citação. Outros aspectos conclusivos foram: dispersão temática, foco de interesse em temas nacionais (Brasil), e concentração da produção científica na região Sudeste. Os dados revelaram ainda uma crescente especialização, contrastando com estudos de caráter mais geral que no passado marcaram o campo. De um lado, isso decorre do padrão de pesquisa adotado nos Mestrados e Doutorados, podendo resultar em maior conhecimento de um determinado assunto; de outro, parece faltar sínteses explicativas necessárias para a compreensão de problemas cujo conhecimento ainda não chegou a um nível satisfatório. Da mesma forma, um tratamento teórico mais sistemático mostra-se necessário para o amadurecimento do campo. Isso contribuiria para esclarecer que é falsa a polêmica sobre o que é mais relevante: estudos de aspectos particulares ou estudos de caráter geral? Isso porque as duas dimensões são igualmente importantes e, sendo assim, separando-as, resvalamos para a metafísica, ou como escreveu Norbert Elias, para a tradição dualista do "isto ou aquilo" (ELIAS, 1994, p. 159). Segundo ele, a divisão excessiva do conhecimento e a crescente especialização acadêmica podem gerar construções de arcabouços conceituais inadequados, separando ou colocando como opostos aquilo que não se deve separar.

No tocante às citações de teses e de dissertações, foi possível constatar que elas foram proporcionalmente baixas em relação às outras fontes pesquisadas, tais como livros, artigos de periódicos, capítulos de livros e jornais. Essa prática suscita de imediato uma indagação, pois se a pesquisa em educação no Brasil está concentrada nos cursos de Pós-Graduação onde naturalmente as teses e dissertações se constituem em produtos da pesquisa científica, por que essas dissertações e teses não se convertem, elas mesmas, em objeto de consulta dos pesquisadores? Por que razão as teses e dissertações são pouco lidas entre nós? Eis um assunto que precisa ser estudado. Aliado a esse aspecto, é visível que, apesar da exigência de publicação de artigos, os pesquisadores desse campo continuam considerando os livros como veículos mais importantes, ao contrário do que predomina em outras áreas do conhecimento.

Quanto à internacionalização, ficou patente que Portugal é o maior parceiro dos historiadores de educação brasileira, o que gera uma interrogação sobre as crescentes exigências de intercâmbio com países de língua inglesa e também uma reflexão sobre os próprios intercâmbios em si. Até que ponto tais exigências inibem relações acadêmicas com países praticantes de outros idiomas? O que dizer de nossas relações acadêmicas - ou da falta delas - com os vizinhos da América Latina, por exemplo? Que tipo de integração buscamos em um mundo cada vez mais globalizado? Os intercâmbios praticados nos últimos anos têm mostrado que o campo da história da educação no Brasil é forte e consolidado: o que desejamos dele ao projetarmos o seu futuro?

Outro aspecto da internacionalização recai sobre as próprias revistas, pois elas são classificadas pelas agências de fomento à pesquisa e um dos critérios para se conseguir estratos mais altos dessa avaliação é a internacionalização, o que gera também disputa entre elas. Considerando que esse padrão acadêmico não é restrito ao Brasil, depreende-se que os pesquisadores estrangeiros têm os mesmos interesses e, assim, também buscam espaço nas revistas. Nesse sentido, a política de compor dossiês que, no caso aqui analisado, visou a internacionalização, 
demonstra também as escolhas epistemológicas e temáticas que representa a hegemonia estabelecida no campo.

Especificamente sobre a questão sdo campo científico como lugar de construção de hegemonias, este estudo permitiu constatar o predomínio da História Cultural, que veio ascendendo a essa posição desde a segunda metade da década de 1990. No caso específico da história da educação, essa visão consolidou-se após um período de intensos debates desde o início da década de 1990 paralelamente à chamada crise de paradigmas. A essa nova hegemonia teórica que mudou as relações de poder no interior do campo vem correspondendo reincidência na direção política da Sociedade Brasileira de História da Educação (SBHE). Considerando que a RBHE é o periódico da SBHE, ela expressa a mesma hegemonia e aqui é preciso levar em conta que, na linha interpretativa de Bourdieu, os periódicos, por serem veículos difusores do conhecimento, convertem-se em locus de disputas internas no campo científico. Se adicionarmos a esse fator a política brasileira de avaliação dos Programas de Pós-Graduação e das agências de fomento à pesquisa, fica mais claro o papel dos periódicos e a disputa por publicações, pois eles funcionam como instrumento ideológico-cultural importante na construção de hegemonia. Desse modo, os artigos que não são aceitos para publicação e que, por isso, se tornam uma linha invisível para o campo, também constituem importante e elucidativo aspecto sobre o seu funcionamento, pois eles são instrumentos e.

Assim, se por um lado, predominam recorrências políticas e teóricas que conferem ao campo uma situação de estabilidade; por outro, elas o petrificam. Pois esses fatores inibem a pluralidade e restringem a possibilidade de alternância na direção da SBHE por pesquisadores que não compõem a atual hegemonia, situação que contrasta com os primeiros anos da entidade. Acreditamos que, se o campo da história da educação cresceu e se fortaleceu nas últimas décadas, é necessário que essa condição seja acompanhada do fortalecimento das diferentes interpretações que existem no seu interior, pois, para a construção desse campo, convergiram tradição e renovação. Além disso, é preciso lembrarmos que o grau de democracia de um país está ligado ao grau de democracia existente nas suas instituições. Em síntese, quanto à situação político-teórica verificada no campo da história da educação desde o final da década de 1990, constatamos que essa nova configuração é similar à estabilidade de posições verificada nos cargos diretivos e demais espaços de micro-poder da Sociedade Brasileira de História da Educação (SBHE). Tal conclusão faz jus à teoria do campo científico de Pierra Bourdieu e Norbert Elias, a qual, portanto, se mostrou adequada como referencial conceitual para efetuarmos a análise dos dados e escrevermos este artigo.

Em nosso levantamento, interessava-nos conhecer autorias, gênero, vinculação institucional dos autores, citações, temas dos artigos e sua abrangência (nacional ou internacional). Esperamos que os dados por nós levantados possam contribuir para ampliar nossa visão sobre um dos aspectos constitutivos da história da educação no Brasil, isto é, a produção acadêmica veiculada nos artigos da principal revista desse campo. Esse conhecimento, acrescido a outros como produção de teses e dissertações, apresentação de trabalhos em eventos e publicação de livros, é importante para o mapeamento da história da educação em âmbito internacional, seu estado atual, suas tendências e desafios. Somos cientes de que a possibilidade de se conhecer essa produção não se converte em solução para os nossos problemas de ordem teórica, mas pode facilitar a formação de grupos, a troca de informações e o intercâmbio que vem sendo praticado em âmbito internacional. 


\section{REFERÊNCIAS:}

ALMEIDA, Elenara Chaves Edler. O Portal de Periódicos da Capes: estudo sobre sua evolução e utilização. 2006. 177f. Dissertação (Mestrado em Desenvolvimento sustentável) - Universidade de Brasília, Brasília, 2006. Disponível em: < http:/ / repositorio.unb.br/handle/10482/2542?mode=full $>$. Acesso em: 12 jan. 2018.

BITTAR, Marisa; SILVA, Márcia Regina da; HAYASHI, Maria Cristina Piumbato Innocentini. Produção científica em dois periódicos da área de educação. Avaliação (Campinas), Sorocaba, v. 16, n. 3, p. 655-674, nov. 2011. Disponível em <http://www.scielo.br/scielo.php?script=sci_arttext\&pid=S1414-40772011000300009\&lng=pt\&nrm=iso >. Acessos em 21 nov. 2017.

BITTAR, Marisa. "Educação profissional": um estudo sobre os trabalhos apresentados no IX Congresso da Sociedade Brasileira de História da Educação (SBHE). In: CURY, Cláudia Engler; VIEIRA, Carlos Eduardo; SIMÕES, Regina Helena Silva (Orgs.) História da Educação: global, nacional e regional. Vitória: EDUFES, 2019. p. 231-248.

BOURDIEU, Pierre. O campo científico. In: ORTIZ, R. (Org.). Pierre Bourdieu: sociologia. 2. ed. São Paulo: Ática, 1994. p. 122-155. (Grandes Cientistas Sociais, 39).

ELIAS, Norbert. A sociedade dos indivíduos. Rio de Janeiro: Zahar Editora. 1994.

FERREIRA Jr., Amarilio. Marxismo, ciências humanas e pesquisa em educação no Brasil: dos primeiros tempos ao século XXI. In: BITTAR, Marisa et al (Org.). Pesquisa em Educação no Brasil: balanços e perspectivas. São Carlos: EdUFSCar, 2012. p. 117-141.

FERREIRA Jr., Amarilio. A influência marxista no PPGE/UFSCar (1976-1991). Revista Eletrônica de Educação (REVEDUC), v. 11, n. 1, p. 86-96, jan./maio, 2017.

GAMBOA, Silvio A. Sanchez. A dialética na pesquisa educacional: elementos de contexto. In: FAZENDA, Ivani (Org.). Metodologia da pesquisa educacional. $6^{\text {a }}$ Ed. São Paulo: Cortez, 2000. p. 93-115.

Hayashi, Maria Cristina Piumbato Innocentini, FERREIRA Jr.; Amarilio et al. História da educação brasileira: a produção científica na biblioteca eletrônica SCIELO. Educação \& Sociedade, abr., 2008, v. 29, n.102, p.181-211.

HAYASHI, Carlos Roberto Massao; FERREIRA Jr., Amarilio. O campo da história da educação no Brasil: um estudo baseado nos grupos de pesquisa. Avaliação (Campinas), 2010, v.15, n.3, p.167-184.

HOFSTETTER, Rita; FONTAINE, Alexandre; HUITRIC, Solenn. Mapping the discipline History o Education. Paedagogica Historica: International Journal of History of Education. N. 50, v. 6, p. 871-880, 2014. 
REVISTA BRASILEIRA DE HISTÓRIA DA EDUCAÇÃO - SBHE. Disponível em: < http://www.rbhe.sbhe.org.br>. Acesso em: 10 mar. 2017.

SAVIANI, Dermeval; CARVALHO, Marta Maria Chagas de; VIDAL, Diana; ALVES, Claudia; GONÇALVES NETO, Wenceslau. Sociedade Brasileira de História da Educação: constituição, organização e realizações. Revista brasileira de história da educação, v. 11, n. 3, p. 13-45, set./dez. 2011.

SOCIEDADE BRASILEIRA DE HISTÓRIA DA EDUCAÇÃO - SBHE. Disponível em: < http://www.sbhe.org.br>. Acesso em: 10 out. 2017.

VANTI, Nadia Aurora Peres. Da Bibliometria à webometria: uma exploração conceitual dos mecanismos utilizados para medir o registro da informação e a difusão do conhecimento. Revista Ciência da Informação, Brasília, v. 31, n. 2, p. 152-162. maio/ago. 2002. Disponível em: < http:/ / revista.ibict.br/ciinf/index.php/ciinf/article/view/171>. Acesso em: 24 out. 2017.

VIEIRA, Carlos Eduardo; GONDRA, José G. Revista Brasileira de História da Educação: trajetória e os desafios da internacionalização (2001-2014). In: SANI, Roberto. History of Education \& Children's Literature. Macerata, v. X, 2015, p. 13-21.

WARDE, Miriam. Contribuições da História para a Educação. Em Aberto. Contribuições das Ciências Humanas para a Educação: a História. V. 9, n. 47, p. 3-10. Jul. -set. 1990.

\section{DADOS DOS AUTORES}

\section{MARisa BitTAR}

Docente do Departamento de Educação da Universidade Federal de São Carlos (UFSCar). bittar@ufscar.br

\section{Olivia Medeiros Neta}

Docente do Departamento de Fundamentos e Políticas - Centro de Educação da Universidade Federal do Rio Grande do Norte (UFRN). olivianeta@gmail.com

\section{Amarilio Ferreira Junior}

Docente do Departamento de Educação da Universidade Federal de São Carlos (UFSCar). ferreira@ufscar.br

Submetido em: 25-6-2020

Aceito em: 17-11-2020 